\title{
Design, Synthesis, Characterization and Toxicity Studies of Poly (N-Iso- Propylacrylamide-co-Lucifer Yellow) Particles for Drug Delivery Applications
}

\author{
Mohsen $\mathbf{R}^{1,2 *}$, Alexander BD1, Richardson SCW', Mitchell JC ${ }^{1}$, Diab AA² and Snowden MJ1 \\ ${ }^{1}$ School of Science, University of Greenwich, Chatham, Kent, ME4 4TB, UK \\ ${ }^{2}$ Faculty of Biotechnology, October University for Modern Sciences and Arts (MSA), Cairo, Egypt
}

\begin{abstract}
A novel fluorescent temperature/pH responsive particle was designed, synthesized, characterised and tested for toxicity. Poly (N-iso-propylacrylamide-co-5\%-lucifer yellow) (p(NIPAM-co-5\% LY)) was prepared using a surfactant free emulsion polymerisation technique. The particles were negatively charged and were approximately $250 \mathrm{~nm}$ at $15^{\circ} \mathrm{C}$. When the particles de-swell following an increase in temperature, a particle size around $100 \mathrm{~nm}$ is obtained. The toxicity of different concentrations of the new particles ( $p$ (NIPAM)-co-5\% LY, as well as the $100 \% p(N I P A M)$ and the main monomer NIPAM was tested on two cell lines (Hela and Vero). The toxicity was tested in comparison to a positive control (dextran sugar) and a negative one (poly(ethylenimine)) (PEI). The results show that the two particles show cell viability over $80 \%$ (for both cell lines Hela and Vero) up to a concentration of $3 \mathrm{mg} / \mathrm{mL}$ while NIPAM monomer showed cell viability over $80 \%$ at a concentration equal to or less than $0.3 \mathrm{mg} / \mathrm{mL}$. The fluorescence property of the novel particles make them traceable. Combining this property (tracing) to the ability of the particles to release their content in response to temperature and $\mathrm{pH}$ change can be a potential drug delivery system for cancer treatment.
\end{abstract}

Keywords: Fluorescent p(NIPAM); Lucifer yellow; Toxicity of p(NIPAM); Drug delivery; Diagnostics

\section{Introduction}

Poly (N-isopropyl acrylamide) (p(NIPAM)) particles are characterised by their ability to change their conformation and physico-chemical properties (such as particle size and surface charge density) according to the change in the surrounding environment such as temperature, $\mathrm{pH}$ and ionic strength [1-5]. This is thought to be a property that can be used in different applications such as drug delivery [6].

Below the volume phase transition temperature (VPTT), the polymer-polymer and polymer-solvent interactions are weak, the interstitial spaces in the nanogel particles are filled with water and the nanogel particles are swollen. Above the VPTT, the polymer-polymer interactions become stronger than the polymer-solvent ones and so the polymer particles tend to collapse (Figure 1). When the temperature is increased, the polymer chains tend to interact with each other rather than with the solvent molecules and the hydrogen bonding between the polymer chains and the solvent molecules is reduced. This causes most of the solvent entrapped within the interstitial spaces of the polymer matrix to be expelled; forming hard like sphere particles and the nanogel tends to shrink. During this collapsed state, the particles are dispersed; this is due to the repulsion between the similar ionic charges on the particle surface caused by the ionic initiators. This process (deswelling) is reversible, so if the temperature goes back below the VPTT, the interactions between the polymer and the solvent improve and the nanogel swells again.

The fact that the volume phase transition temperature (VPTT) of NIPAM based nanoparticles $\left(32-34^{\circ} \mathrm{C}\right)$ [3] is very close to the human body temperature $\left(37^{\circ} \mathrm{C}\right)$ makes them a good choice for biomedical applications. As an example of suggested drug delivery applications based on temperature trigger, the particles are swollen at room temperature (around $25^{\circ} \mathrm{C}$ which is below the VPTT), so, if they incorporate a drug in its matrix, when administered in the human body VPTT, it will deswell and release the drug. Many researchers suggested drug delivery [7-9], diagnostics [10] and protein binding [11-13] applications of NIPAM-based nanoparticles.
Nanogels sensitive to both temperature and $\mathrm{pH}$ can be prepared by incorporating acidic or basic co-monomers into poly (NIPAM) nanogel matrix. An example of this is the poly (NIPAM)-co-acrylic acid nanogel [1]. Figure 1 shows the effect of temperature and $\mathrm{pH}$ on the temperature/pH sensitive $\mathrm{p}$ (NIPAM)-co-acrylic acid particles. At temperature lower than the VPTT, the particles take in solvent molecules (water) and hydrogen bonds are formed between them (the particles and the water molecules). When the temperature exceeds the VPTT, the hydrogen bonds are broken and the particles collapse (Figure 1) [1]. The $\mathrm{pH}$ conformational transition point depends upon the logarithm of the acid dissociation constant $\left(\mathrm{pK}_{\mathrm{a}}\right)$ of the functional groups incorporated. At $\mathrm{pH}$ below the $\mathrm{p} K_{\mathrm{a}}$ of acrylic acid, the nanogel particles are collapsed (due to low electrostatic repulsion forces (E.R.F) but when the $\mathrm{pH}$ is more than the $\mathrm{p} K$, the E.R.F. between the ionised acrylic acid molecules within the polymer matrix increase causing the gel to acquire a more swollen configuration (Figure 1). In Figure 1, the blue colour represents low temperature (below the VPTT) and high pH (higher than the $\mathrm{p} K_{\mathrm{a}}$ ), the red colour represents high temperature and low $\mathrm{pH}$. Both cases (low temperature/low $\mathrm{pH}$ and high temperature/ high $\mathrm{pH}$ ) are represented as light blue.

The incorporation of a fluorescent dye such as Lucifer yellow (LY) to $\mathrm{p}$ (NIPAM) particles adds a new function (colour and fluorescence) that makes it traceable. This suggests new applications especially in the field of diagnosis of different diseases either in vivo or in vitro.

*Corresponding author: Reham Mohsen, School of Science, University of Greenwich, Chatham, Kent, ME4 4TB, UK, Tel: 44 (0)20 8331 9800; Fax: 44 (0)20 8331 9805; E-mail: r.m.momee@greenwich.ac.uk

Received March 03, 2016; Accepted March 21, 2016; Published April 02, 2016

Citation: Mohsen R, Alexander BD, Richardson SCW, Mitchell JC, Diab AA, et al. (2016) Design, Synthesis, Characterization and Toxicity Studies of Poly ( $\mathrm{N}$-IsoPropylacrylamide-co-Lucifer Yellow) Particles for Drug Delivery Applications. J Nanomed Nanotechnol 7: 363. doi:10.4172/2157-7439.1000363

Copyright: ( 2016 Mohsen $\mathrm{R}$, et al. This is an open-access article distributed under the terms of the Creative Commons Attribution License, which permits unrestricted use, distribution, and reproduction in any medium, provided the original author and source are credited. 
Citation: Mohsen R, Alexander BD, Richardson SCW, Mitchell JC, Diab AA, et al. (2016) Design, Synthesis, Characterization and Toxicity Studies of Poly (N-Iso-Propylacrylamide-co-Lucifer Yellow) Particles for Drug Delivery Applications. J Nanomed Nanotechnol 7: 363. doi:10.4172/21577439.1000363

Page 2 of 10

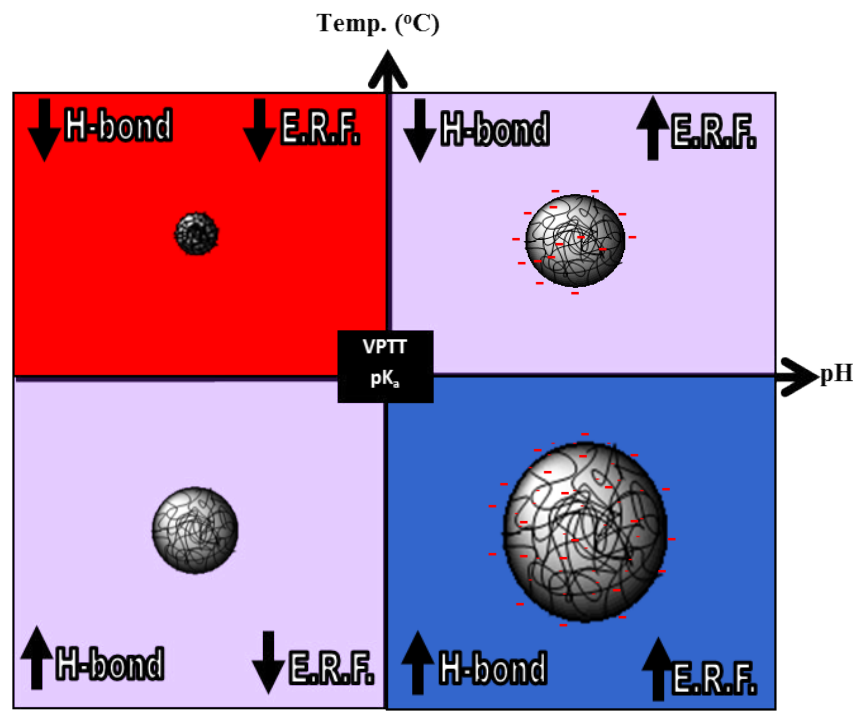

Figure 1: A schematic diagram representing the effect of temperature and $\mathrm{pH}$ on a typical temperature/pH responsive microgel particle.

Combining the previously suggested drug delivery applications of nanogels [7-9] to its ability to being traced in the human body can be a promising system for combined diagnosis and delivery of drugs to suitable environments $[14,15]$.

In this work, a novel nanoparticle, p(NIPAM-co-5\% LY), is synthesized and characterized using DLS (particle size and electrophoretic mobility), infrared spectroscopy, scanning electron microscopy and fluorescence microscopy. Being a candidate for biomedical applications, the toxicity was tested using two cell lines: kidney cells (Vero) and breast cancer cells (HeLa).

\section{Lucifer yellow VS}

Lucifer yellow VS dilithium is a water soluble fluorescent dye of molecular weight $550.39 \mathrm{~g} / \mathrm{mol}$ [16]. Due to the presence of 3 benzene rings, it is hydrophobic in nature. It has two excitation wavelengths (430 and $280 \mathrm{~nm}$ ) and emission wavelength at $540 \mathrm{~nm}$ [17]. Lucifer yellow is used for different biomedical applications including marking cells, neurons, albumin, cholesterol, phospholipids, collagenase, polynucleotides, progesterone derivatives, testosterone, estriol [16], and tracers of cell-cell fusion [18]. It is also selectively binds to copper [19] which can be used in industrial and environmental applications.

The logarithm of acid dissociation constant $\left(\mathrm{pK}_{\mathrm{a}}\right)$ of LY was calculated using the online database $\mathrm{ACD} / \mathrm{labs}$ [20]. The presence of more than one ionisable group in the molecular structure of LY (Figure 2) results in more than one $\mathrm{p} K$, these are; $-2.2(0.6),-0.7(0.5), 1.4(0.8)$ and $5.7(0.8)$ where standard deviations are shown between brackets. Figure 2 shows the protonation state of LY versus $\mathrm{pH}$. The most acidic form is coloured red and the most alkaline one is coloured blue. The two negative $\mathrm{p} K$ a values are mainly caused by the protonation/ deprotonation of the sulphonate groups (groups 1 and 2 (coloured in red)) (Figure 2). The first positive $\mathrm{p} K_{\mathrm{a}}$ is caused by the protonation/ deprotonation of the nitrogen in the piperidine ring (group 3 (coloured in light blue)) while the second one is caused by the amino of the aniline (group 4 (coloured in blue)) [1]. An overview of the protonation state of lucifer yellow at different $\mathrm{pH}$ values is shown in Figure 3 [1].

From polymerization point of view, lucifer yellow VS dilithium salt is a perfect choice. This is due to the presence of a pendant vinyl group (coloured in grey) (Figure 2) which makes it readily polymerizable with other monomers under suitable conditions. This is important for synthesizing monodispersed particles with the similar electrophoretic mobilities. On the other hand, a disadvantage of using lucifer yellow is its relatively low molar extinction coefficient $(\varepsilon)$ of $12000 \mathrm{M}^{-1} \mathrm{~cm}^{-1}$ $[17,21,22]$ when compared to other fluorophores such as fluorescein isothiocyanate (FITC) with a molar excitation co-efficient of $75000 \mathrm{M}^{-1}$ $\mathrm{cm}^{-1}$ [23], texas red $\left(\varepsilon=85000 \mathrm{M}^{-1} \mathrm{~cm}^{-1}[24]\right.$ and tetramethyl rhodamine isothiocyanate (TRITC) with an $\varepsilon$ of $100000 \mathrm{M}^{-1} \mathrm{~cm}^{-1}$ [23]. It is also characterised by a relatively low quantum yield (21\%) [25] compared to other fluorophores such as rhodamine 6G (95\%), fluorescein (95\%) and quinine sulphate (58\%) [26].

\section{Materials and Methods}

\section{Materials}

N-isopropylacrylamide (NIPAM) 97\% (Aldrich), lucifer yellow (LY) (Aldrich), N, N'-methylenebisacrylamide 99\% (Aldrich), potassium persulphate 98\% (BDH Laboratory Suppliers), branched poly(ethylenimine) (PEI) of molecular weight $25 \mathrm{kD}$ (Cat. 18197-8) (Aldrich) were obtained from commercial suppliers and used without further purification. Vero CCL-81 (normal kidney of Cercopithecus aethiops) and HeLa CCL2 (human cervical epithelial cells) from ATCC company. Media were purchased from Gibco Life Technologies. For Vero cells, Dulbecco's Modified Eagle Medium (DMEM) was used while for HeLa cells, Minimum Essential Medium (MEM) was used. Penicillin-Streptomycin-Glutamine (PSG) (100x) and fetal Bovine Serum (FBS) were purchased from Gibco life technologies. (3-(4,5-Dimethylthiazol-2-yl)-2,5-diphenyltetrazolium bromide (MTT) was purchased from Sigma Aldrich UK.

\section{Methods}

Synthesis of p(NIPAM-co-5\% LY): In a $1 \mathrm{~L}$ reaction vessel, $0.5 \mathrm{~g}$ of the initiator (potassium per sulphate) was dissolved in $800 \mathrm{~mL}$ of

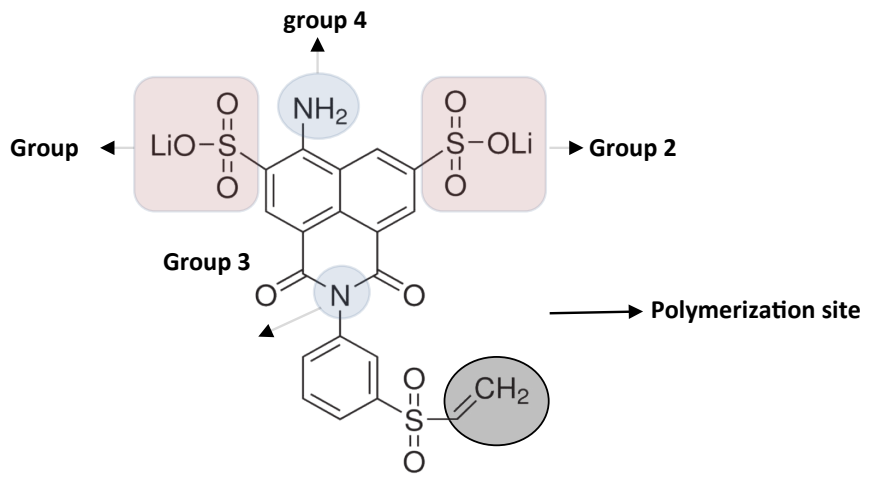

Figure 2: Molecular structure of lucifer yellow VS dilithium salt [2].

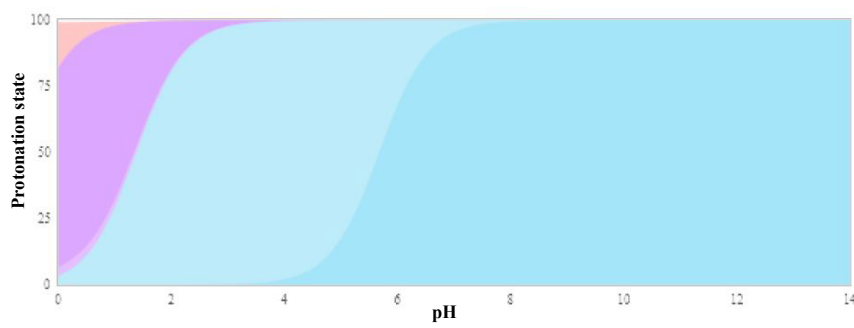

Figure 3: Protonation state of lucifer yellow versus $\mathrm{pH}$ [1]. 
Citation: Mohsen R, Alexander BD, Richardson SCW, Mitchell JC, Diab AA, et al. (2016) Design, Synthesis, Characterization and Toxicity Studies of Poly (N-Iso-Propylacrylamide-co-Lucifer Yellow) Particles for Drug Delivery Applications. J Nanomed Nanotechnol 7: 363. doi:10.4172/21577439.1000363

Page 3 of 10

distilled water. A three-necked lid was clamped to the reaction vessel, which was then heated to $70^{\circ} \mathrm{C}$ with continuous stirring. Monomer (4.75 g NIPAM), co-monomer (0.25 g lucifer yellow (LY)) and cross linker ( $0.5 \mathrm{~g} \mathrm{~N}, N^{\prime}$-methylenebisacrylamide) were stirred in distilled water $(200 \mathrm{~mL})$ and transferred into the reaction vessel containing the initiator and continuously stirred at $70^{\circ} \mathrm{C}$ for six hours under an inert atmosphere of nitrogen. When the reaction was complete, the nanogel dispersion was allowed to cool to room temperature. The nanogel was dialyzed in fresh de-ionised water for a week (changed daily), centrifuged and freeze dried.

Dynamic light scattering (DLS): Dynamic light scattering (DLS) measurements were carried out using a Malvern Zetasizer Nano ZS. The hydrodynamic diameter of the particles was measured in response to temperature in the 15 to $60^{\circ} \mathrm{C}$ range. All samples were diluted with deionized water $(1 \mathrm{~mL}$ of dialysed microgel dispersion was diluted with $2 \mathrm{~mL}$ of water) before measurements. A quartz cuvette with two polished windows (Starna Type 1) was used for all the measurements and the temperature of the dispersion was controlled by a Peltier thermocouple. Data for $\mathrm{p}$ (NIPAM-co-5\% LY) measurements were collected every $1{ }^{\circ} \mathrm{C}$ and the samples were equilibrated for 2 min before each data collection point. Three measurements, each consisting of 13 subruns, were taken at each temperature to obtain an average hydrodynamic diameter. Experiments were also conducted where the $\mathrm{pH}$ of the samples was adjusted to different $\mathrm{pH}$ values using $\mathrm{HCl}$ and $\mathrm{NaOH}$ to test for the effect of changing $\mathrm{pH}$ upon the size of the particles. The electrophoretic mobility of $\mathrm{p}$ (NIPAM-co-5\% LY) in a salt concentration of $1 \times 10^{-4} \mathrm{M} \mathrm{NaCl}$ was measured in response to temperature change across the range of $15-60^{\circ} \mathrm{C}$ using a disposable folded capillary cell.

Fluorescence spectroscopy: A Horiba Jobin Yvon Fluoromax 4 spectrofluorometer was used for fluorescence experiments. All samples were excited at $430 \mathrm{~nm}$ and the full emission spectra $(450-1050 \mathrm{~nm})$ were recorded with bandwidth of $5 \mathrm{~nm}$ at $25^{\circ} \mathrm{C}$. A $10 \mathrm{~mm}$ path length quartz cuvette with four polished windows (Starna Type 3) was used for all the measurements.

Infrared spectroscopy (IR): A Thermo Nicolet Nexus FT-IR was used to carry out the IR experiment in this work. Nanoparticle dispersions were dialysed and freeze-dried then the solid samples (powder) were used for IR experiments using attenuated total reflection (ATR) ZnSe crystal.

\section{Microscopy}

Scanning electron microscopy: A Hitachi SU8030 cold cathode filled emission gun scanning electron microscope was used to obtain images of the particles.

Fluorescence microscopy: A Nikon Eclipse 90i microscope, fitted with a fluorescein isothiocyanate filter (FITC) and a Nikon digital sight DS-U3 camera were used to take fluorescent images of the particles. Plan Fluor 100x oil Ph3 DLL lens was used with working distance of $0.16 \mathrm{~mm}$. The numerical aperture of the images was 1.3 , refractive index 1.5 and exposure time $3 \mathrm{~s}$. the sample was placed on a microscopic slide, left to dry in air and then immersion oil was added on it.

\section{Toxicity studies}

Sterilization: All the pipetting tips, phosphate buffered saline (PBS), glassware, magnetic stirrers, spatulas used in this experiment were sterilized used an Astell autoclave at $121^{\circ} \mathrm{C}$ for 85 minutes.

Preparation of media: To prepare a complete media, $50 \mathrm{~mL}$ PSG $(100 \mathrm{x})$ and $5 \mathrm{~mL}$ Fetal Bovine Serum (FBS) were added (without any dilution) to a $500 \mathrm{~mL}$ media bottle (either DMEM or MEM). Media were kept in the fridge at $4^{\circ} \mathrm{C}$.

Cell sub-culturing: In a clean and sterile class II laminar flow hood, the media in the flask were removed using a disposable sterile $10 \mathrm{~mL}$ serological pipette (Fisher brand). The flask was then washed with 10 $\mathrm{mL}$ of sterilised phosphate buffered saline (PBS) 3 times (using a new serological pipette each time). Trypsin EDTA $(0.5 \mathrm{~mL})$ was added and spread among the flask which is then placed in an incubator (Thermo Scientific HERACELL $150 \mathrm{i} \mathrm{CO}$ incubator) at $37^{\circ} \mathrm{C}$ and $5 \% \mathrm{CO}_{2} \mathrm{v} / \mathrm{v}$ for 5-7 minutes after which the viability of cells was checked under microscope (Nikon Japan with a x10 ELWD lenswith working distance 2.62-1.8 mm). After that, $10 \mathrm{~mL}$ of fresh media (MEM for HeLa and DMEM for Vero cells) were added to the flask and well mixed with the cells, and then $9 \mathrm{~mL}$ of the media (now mixed with cells) were removed and put in an Eppendorf tube to be used for the seeding step. Fresh media $(9 \mathrm{~mL})$ were then added to the flask, mixed then put in the incubator. Cells were split twice weekly.

Cell seeding: Cell count (using a haemocytometer) of the cell suspension from the splitting step ( $9 \mathrm{~mL}$ removed after using trypsin) was carried out. Accordingly, a cell suspension of a concentration $(1 \times$ $10^{4} \mathrm{cell} / \mathrm{mL}$ ) was prepared. In a 96-well plate (excluding the peripheral cells, these are columns 1 and 12 and rows A and H (Figure 4)), $100 \mu \mathrm{L}$ of the freshly prepared cell suspension were placed in each well. The plate was then put in the incubator for 24 hours.

Sample preparation: In an autoclaved beaker, the sample (either dextran, NIPAM monomer, $\mathrm{p}$ (NIPAM), p(NIPAM-co-5\% LY) or PEI) is weighed. Sterile fresh media (MEM for HeLa and DMEM for Vero cells) was added and left stirring for an hour. In a sterile class II laminar flow hood, the sample dispersion/solution was filtered using a single use filter unit with a pore size of $2 \mu \mathrm{m}$ (Minisart ${ }^{\star}$ Sartorius stedium biotech). A serial dilution was then prepared and used for cell dosing.

Cell dosing: The previously seeded 96-well plates are placed in a clean and sterile fume cupboard, the $100 \mu \mathrm{L}$ of media (in each well) are removed using sterile pipette tips. The first two columns are used as control wells $(100 \mu \mathrm{L}$ of fresh media is put in each well) while the rest of the columns is used for the different concentrations of the sample. In each well, $100 \mu \mathrm{L}$ of the pre-prepared sample-media suspension is accurately put using a sterile pipette tip. For each sample, two plates are set up; Figure 4 shows the design of each plate while Table 1 shows the concentrations used in each one. For each cell line (HeLa and Vero), a whole plate was set up to be a control one. Plates are placed in the incubator for 72 hours after which the MTT assay is carried out.

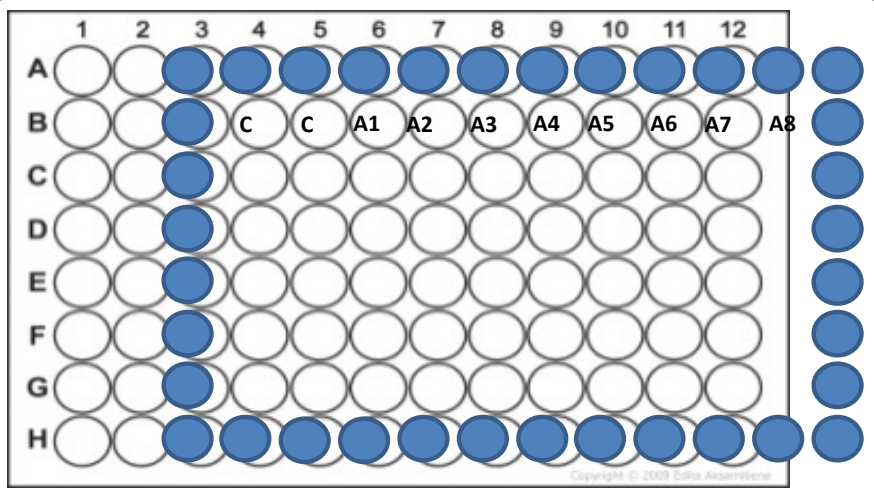

Figure 4: Structure and organisation of the 96- well plates used for toxicity studies. Blue cells were kept empty. The concentrations of the columns are shown in Table 1. 
Citation: Mohsen R, Alexander BD, Richardson SCW, Mitchell JC, Diab AA, et al. (2016) Design, Synthesis, Characterization and Toxicity Studies of Poly (N-Iso-Propylacrylamide-co-Lucifer Yellow) Particles for Drug Delivery Applications. J Nanomed Nanotechnol 7: 363. doi:10.4172/21577439.1000363

Page 4 of 10

\begin{tabular}{|c|c|c|c|c|c|c|c|c|c|c|}
\hline Conc. & C & C & A1 & A2 & A3 & A4 & A5 & A6 & A7 & A8 \\
\hline \multicolumn{11}{|l|}{ Plate A } \\
\hline $\mathrm{mg} / \mathrm{mL}$ & Control & Control & 3.00 & 1.00 & 0.70 & 0.30 & 0.10 & 0.07 & 0.03 & 0.01 \\
\hline \multicolumn{11}{|l|}{ Plate B } \\
\hline$\mu \mathrm{g} / \mathrm{mL}$ & Control & Control & 7.00 & 3.00 & 1.00 & 0.70 & 0.30 & 0.10 & 0.07 & 0.03 \\
\hline
\end{tabular}

Table 1: The design of plates $A$ and $B$ and the concentrations used for the toxicity testing of dextran, NIPAM monomer, p(NIPAM), p(NIPAM-co-5\% LY) and poly(ethylenimine) (PEI).

The concentrations of the columns are shown in Table 1.

MTT assay: For the preparation of MTT solution, $250 \mathrm{mg}$ of MTT reagent were dissolved in PBS and sterilised at $121^{\circ} \mathrm{C}$ for 85 minutes. In each well, $10 \mu \mathrm{L}$ of pre-prepared of MTT solution was added. Plates were then placed in the incubator and left for 4 hours. The media was then removed (this includes $100 \mu \mathrm{L}$ sample in media and $10 \mu \mathrm{L}$ MTT) and $100 \mu \mathrm{L}$ of dimethyl sulphoxide (DMSO) are added in each well and plates are left in the incubator for 30 minutes. The absorbance at $540 \mathrm{~nm}$ of the DMSO in each well is then determined using a Thermo Electron Corporation Multiskan Ascent plate reader.

Growth curves: Cells were seeded at a concentration of $1 \times 10^{4}$ cell/ $\mathrm{mL}$ (as explained above) in a 96-well plate. Every day (for 10 days), MTT assay was carried out (as explained above) on one column of the plate.

\section{Results and Discussion}

\section{Particle size}

Effect of temperature on the particle size: Figure 5 shows the response of $\mathrm{p}$ (NIPAM-co-5\% LY) to the change in temperature across a temperature range of $15-60^{\circ} \mathrm{C}$ both during heating and cooling. The initial particle size at $15^{\circ} \mathrm{C}$ at $\mathrm{pH} 7$ is $250 \mathrm{~nm}$ which is considerably smaller than that of $100 \% \mathrm{p}$ (NIPAM) with an initial particle size of 550 $\mathrm{nm}[3,27]$. The incorporation of a hydrophobic co-monomer such as lucifer yellow [28] decreases the extent of hydrogen bonding between the particle and water (solvent) compared to $100 \%$ p(NIPAM), so, less water will be incorporated in the particle leading to a smaller particle size [29]. It also changes the reaction conditions such as the rate of the reaction, solubility of the monomer and co-monomer and the extent of reaction before termination [30]. The DLS data suggest that LY was successfully incorporated in the new particle. The Figure also shows that the novel fluorescent nanoparticle maintains the reversible temperature responsive behaviour of $\mathrm{p}$ (NIPAM) with a VPTT comparable to that of $100 \% \mathrm{p}$ (NIPAM) which is $35^{\circ} \mathrm{C}$ [3]. The polydispersity index (PdI) value (Figure 5 ), which is close to zero (0.04), suggests that the majority of the particles in the dispersion acquire an even size.

Effect of $\mathrm{pH}$ on the particle size of p(NIPAM)-co- $5 \%$ LY: The effect of $\mathrm{pH}$ on the hydrodynamic diameter of $\mathrm{p}$ (NIPAM-co-5\% LY) is shown in Figure 6. The Figure shows an increase in the particle size by increasing the $\mathrm{pH}$ at the same temperature $\left(25^{\circ} \mathrm{C}\right)$. At $\mathrm{pH}(0.5-3)$, the particle diameter was $190 \mathrm{~nm}$ and increased by $20 \%$ to reach $230 \mathrm{~nm}$ at $\mathrm{pH}(5-10)$. At $\mathrm{pH} 11$, the particle further swells by $9 \%$ to reach 248 $\mathrm{nm}$. The change in particle size is thought to be mainly attributed to the change of the protonation state of the co-monomer lucifer yellow by the change in $\mathrm{pH}$ (Figure 3).

Several $\mathrm{pH}$ sensitive NIPAM based particles (with different comonomers such as acrylic acid) have been studied [3]. At $\mathrm{pH}$ lower than the $\mathrm{p} K_{\mathrm{a}}$ of the co-monomer, the anionic groups are protonated, accordingly, they are not charged and hence the electrostatic repulsion force is minimal. When the $\mathrm{pH}$ increases above the $\mathrm{p} K_{\mathrm{a}}$ of the co-

monomer, the anionic co-monomer groups are deprotonated, creating more surface charge on the particle, leading to more electrostatic repulsion forces and hence the increase in the particle size.

Lucifer yellow VS shows two positive $\mathrm{p} K_{\mathrm{a}}$ values (1.4 (0.8) and 5.7 (0.9)) [1]. Figure 6 shows the change in the hydrodynamic diameter of $\mathrm{p}$ (NIPAM)-co-5\%LY according to the change of $\mathrm{pH}$. The first positive $\mathrm{p} K_{\mathrm{a}}$ of LY (1.4) (caused by the deprotonation of the nitrogen of the piperidine ring) [1] shows a minimal effect on the particle size (Figure 6). Comparing the particle size at $\mathrm{pH} 0.5$ to that at $\mathrm{pH} 3$ shows minimal change in the particle size at the two cases. An increase in the particle size around the $\mathrm{pH}$ of 5 which is in the range of the second positive $\mathrm{pK}$ of LY (caused by the deprotonation of the amino group (Figures 2 and 3 ) [1] is observed. The Figure shows $23 \%$ increase in particle size by increasing the $\mathrm{pH}$ from 3 to 5 .

At pH below 5.7 ( \pm 0.9$), \mathrm{p}$ (NIPAM)-co-5\% LY can be considered as a zwitterionic particle. The negative surface charge on $\mathrm{p}$ (NIPAM-co-5\% LY) particles is caused by the $\mathrm{SO}_{4}$ - groups from the anionic initiator used during the particle synthesis $\left(\mathrm{K}_{2} \mathrm{SO}_{4}\right)$ and the fluorescent dye (lucifer yellow) with sulphonate groups (Figure 2). Having two negative $\mathrm{p} K_{\mathrm{a}}$ values, the sulphonate groups of lucifer yellow are deprotonated when the $\mathrm{pH}$ is above zero (Figures 2 and 3) [1]. At pH below 1.4, the nitrogen group of the piperidine ring and the amino group of the aniline are both protonated creating positive charge that masks some of the negative charge created by the initiator and the sulphonate groups of $\mathrm{LY}$. At $1.4<\mathrm{pH}>5.7$, the nitrogen of the piperidine is deprotonated, but the tertiary amine group of the aniline is protonated and thus charged, so, positive charge caused by the protonated amino group

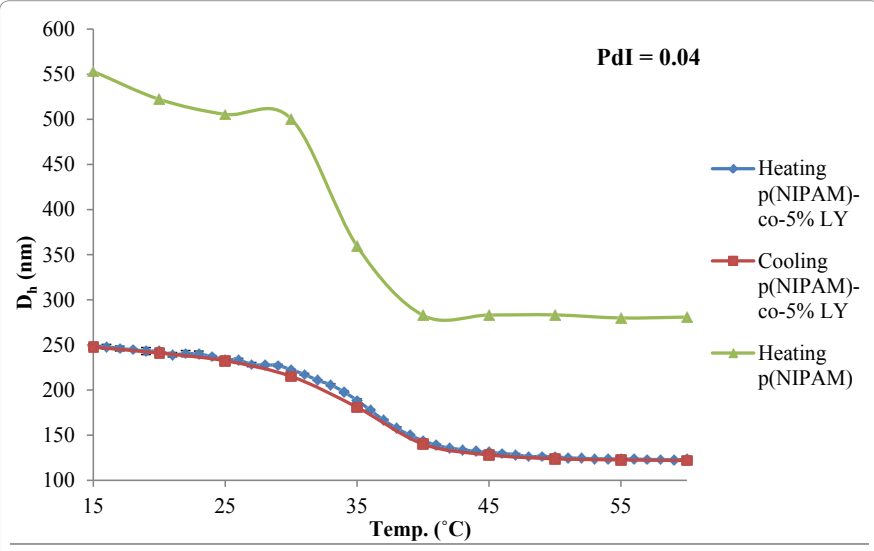

Figure 5: The effect of temperature on the particle size of $p$ (NIPAM-co-5\% LY) at $\mathrm{pH} 7$ across temperature range $\left(15-60^{\circ} \mathrm{C}\right)$

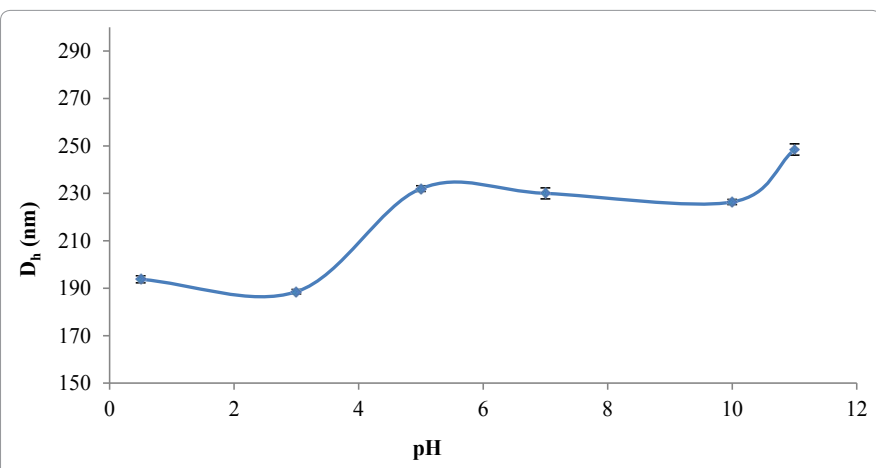

Figure 6: The effect of $\mathrm{pH}$ on the hydrodynamic diameter of $\mathrm{p}(\mathrm{NIPAM})-\mathrm{co}-5 \%$ $\mathrm{LY}$ at $25^{\circ} \mathrm{C}$. 
Citation: Mohsen R, Alexander BD, Richardson SCW, Mitchell JC, Diab AA, et al. (2016) Design, Synthesis, Characterization and Toxicity Studies of Poly (N-Iso-Propylacrylamide-co-Lucifer Yellow) Particles for Drug Delivery Applications. J Nanomed Nanotechnol 7: 363. doi:10.4172/21577439.1000363

Page 5 of 10

can still mask some of the negative charges. When the $\mathrm{pH}$ exceeds 5.7 $( \pm 0.9)$, both groups (nitrogen of piperidine and amino of aniline) are deprotonated and thus no positive charges are created. At this point, the negative surface charge on $\mathrm{p}$ (NIPAM)-co-5\% LY is maximal and not masked by positive charges (the particle is not zwitterionic anymore and tends to only carry negative charges on its surface. This increases the electrostatic repulsion within the particle and hence increases the particle size (Figure 5).

It is worth mentioning that the magnitude of change in the particle diameter of $\mathrm{p}$ (NIPAM)-co-5\% LY at different $\mathrm{pH}$ values is less than that of previously known temperature/ $\mathrm{pH}$ responsive particles such as $\mathrm{p}$ (NIPAM) $-c o-5 \%$ AA [3]. The initial particle diameter of $\mathrm{p}$ (NIPAM)-co-5\% AA at $15^{\circ} \mathrm{C}$ at $\mathrm{pH} 3$ is $290 \mathrm{~nm}$ while at $\mathrm{pH} 6$ (at the same temperature) is $550 \mathrm{~nm}$ [3]. This shows a $90 \%$ increase in the particle size by changing the $\mathrm{pH}$ of the particle dispersion. In the case of $\mathrm{p}$ (NIPAM-co-5\% LY), the particles only show a $32 \%$ increase in diameter when the $\mathrm{pH}$ is changed from 0.5 to 11 .

The magnitude of particle size change in response to $\mathrm{pH}$ change can be increased by incorporating another co-monomer. This has been carried out by many researchers such as the incorporation of AA (3), $\mathrm{N}$ - $t$-butylacrylamide [31].The suggested result then is the synthesis of a fluorescent temperature/pH sensitive particle with a higher magnitude of $\mathrm{pH}$ sensitivity.

\section{Electrophoretic mobility}

Effect of temperature on the electrophoretic mobility: Figure 7 compares between the electrophoretic mobility of $p$ (NIPAM) and $\mathrm{p}$ (NIPAM)-co-5\% LY. $\mathrm{p}$ (NIPAM) has a negative surface charge due to the anionic initiator (potassium persulphate) used during synthesis while $\mathrm{p}$ (NIPAM)-co-5\% LY has a negative surface charge due to both the initiator and the anionic co-monomer (LY) [32].

The Figure shows that at $15^{\circ} \mathrm{C}$ the electrophoretic mobility of $\mathrm{p}$ (NIPAM-co-5\% LY) $(-0.32 \mu \mathrm{mcm} / \mathrm{Vs})$ is higher than that of $\mathrm{p}$ (NIPAM) $(-0.17 \mu \mathrm{mcm} / \mathrm{Vs})$. This can be attributed to two main reasons; first, the presence of a higher surface charge density on p(NIPAM-co-5\% LY) particles due to the addition of an anionic co-monomer (lucifer yellow) [32] beside the anionic initiator (potassium persulphate) used during the synthesis. Second, is that the particle size of p(NIPAM-co-5\% LY) is smaller than that of $\mathrm{p}$ (NIPAM) which causes the particles to move faster. When the temperature exceeds the VPTT $\left(35^{\circ} \mathrm{C}\right)$, the particle deswells which results in a higher surface charge density [29] leading to a higher electrophoretic mobility.

Effect of $\mathbf{p H}$ on the electrophoretic mobility: The effect of $\mathrm{pH}$ on the electrophoretic mobility of p(NIPAM)-co-5\% LY in $1 \times 10^{-4}$ $\mathrm{M} \mathrm{NaCl}$ at $25^{\circ} \mathrm{C}$ is shown in Figure 8. The data of the electrophoretic mobility versus $\mathrm{pH}$ shown in Figure 8 are comparable to those of the particle size shown in Figure 5. As discussed above (point 3.1.1.2), the electrophoretic mobility increases around the $\mathrm{p} K_{\mathrm{a}}$ of LY $(5.7(0.9))$ due to the deprotonation of the amino group of the aniline [1] (Figure 2) that causes an increase of the net negative charge on the particle surface.

\section{Fluorescence spectroscopy}

The fluorescence spectra of $0.01 \mu \mathrm{g} / \mathrm{mL} \mathrm{LY}, 0.2 \mu \mathrm{g} / \mathrm{mL} \mathrm{p}$ (NIPAM) and $0.2 \mu \mathrm{g} / \mathrm{mL}$ p(NIPAM-co-5\% LY) excited at $430 \mathrm{~nm}$ at $25^{\circ} \mathrm{C}$ and $45^{\circ} \mathrm{C}$ at $\mathrm{pH} 3$ and 7 are shown in Figures 9 and 10.

The emission spectra of lucifer yellow at $\mathrm{pH} 7$ at temperatures $25^{\circ} \mathrm{C}$ and $45^{\circ} \mathrm{C}$ (Figure 9) and at $25^{\circ} \mathrm{C} \mathrm{pH} 3$ and 7 (Figure 10) display an emission band at $532 \mathrm{~nm}$ which is comparable to the reported emission wavelength of lucifer yellow at $540 \mathrm{~nm}$ [17]. The emission spectra of $\mathrm{p}$ (NIPAM)-co-5\% LY at $\mathrm{pH} 3$ and 7 and at $25^{\circ} \mathrm{C}$ and $45^{\circ} \mathrm{C}$ (Figures 9 and 10) show an emission band at $520 \mathrm{~nm}$. Accordingly, a blue shift is observed when the fluorophore LY was incorporated into p(NIPAM). This is due to the change in the environment around the LY such as the electronic cloud in the polymer particle $p$ (NIPAM) as well as the polarity of the solvent [18]. The shift of the emission band also provides evidence (together with the DLS and IR) of the incorporation of LY in the new nanoparticle.

Effect of addition of lucifer yellow: The concentration of LY used for the fluorescence spectra in Figures 9 and $10(0.01 \mu \mathrm{g} / \mathrm{mL})$ is the theoretical concentration of LY incorporated in $0.2 \mu \mathrm{g} / \mathrm{mL}$ p(NIPAMco-5\% LY) (5\%), in other words, it is the concentration of LY added during the synthesis of $\mathrm{p}$ (NIPAM)-co-5\% LY, and was selected to give a qualitative comparison of the emission spectrum intensity. However, the fluorescence intensity of LY is significantly higher than that of p(NIPAM-co-5\% LY) which suggests that either not all the LY added during the synthesis reaction is incorporated in the new particle, or the quantum yield of LY was quenched by the p(NIPAM) particles, or other environmental conditions such as solvent polarity [18]. The second suggestion is supported by Furstenberg et al. [18] who studied the excited state dynamics of lucifer yellow and concluded that LY is an environment sensitive probe whose fluorescence dynamics change in the presence of proteins and by changing the solvent. They also concluded that the fluorescence of LY is quenched by amino acids. Given the fact that both proteins and polymer particles are considered as large complex molecules/particles, it is a possibility that polymer particles might have similar quenching effect on the fluorescence of LY.

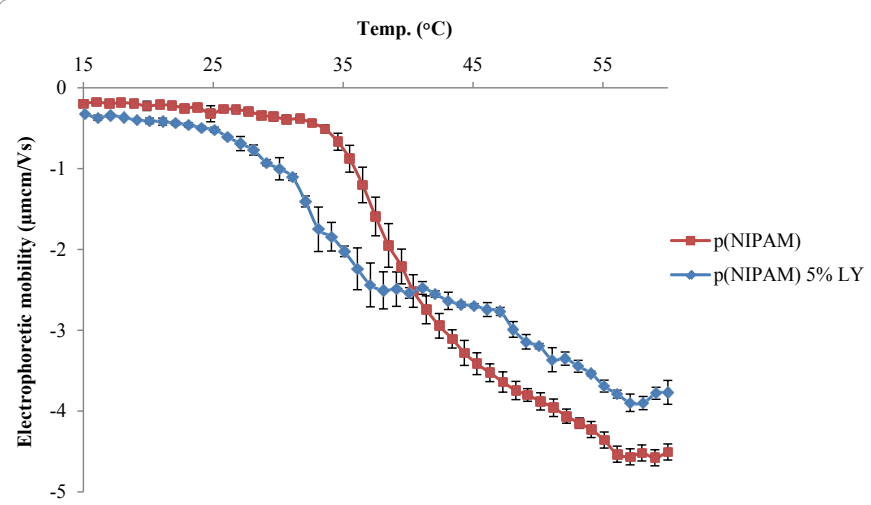

Figure 7: The effect of temperature (heating) across a range $\left(15-60^{\circ} \mathrm{C}\right)$ on the electrophoretic mobility of $\mathrm{p}$ (NIPAM-co-5\% LY) and $\mathrm{p}$ (NIPAM) in $10-4 \mathrm{M} \mathrm{NaCl}$ at $\mathrm{pH} 7$.

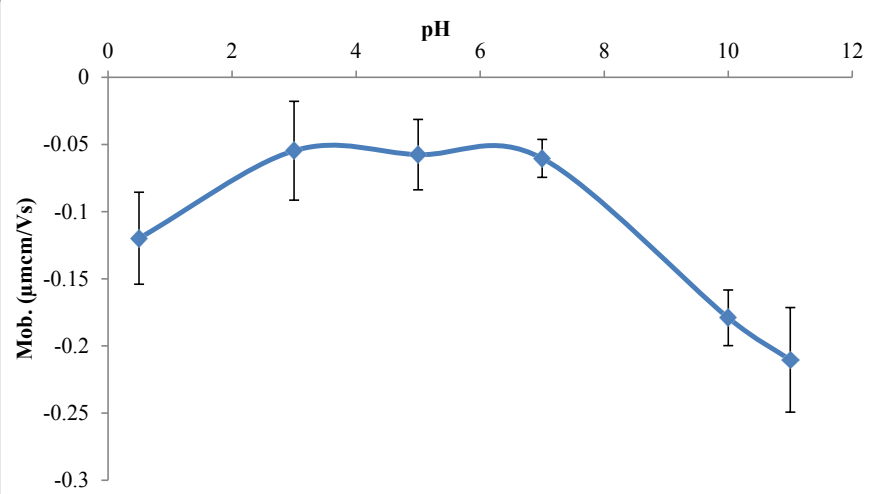

Figure 8: The effect of $\mathrm{pH}$ on the electrophoretic mobility of $\mathrm{p}$ (NIPAM-co-5\% LY) in $1 \times 10-4 \mathrm{M} \mathrm{NaCl}$ at $25^{\circ} \mathrm{C}$. 
Citation: Mohsen R, Alexander BD, Richardson SCW, Mitchell JC, Diab AA, et al. (2016) Design, Synthesis, Characterization and Toxicity Studies of Poly (N-Iso-Propylacrylamide-co-Lucifer Yellow) Particles for Drug Delivery Applications. J Nanomed Nanotechnol 7: 363. doi:10.4172/21577439.1000363

Page 6 of 10

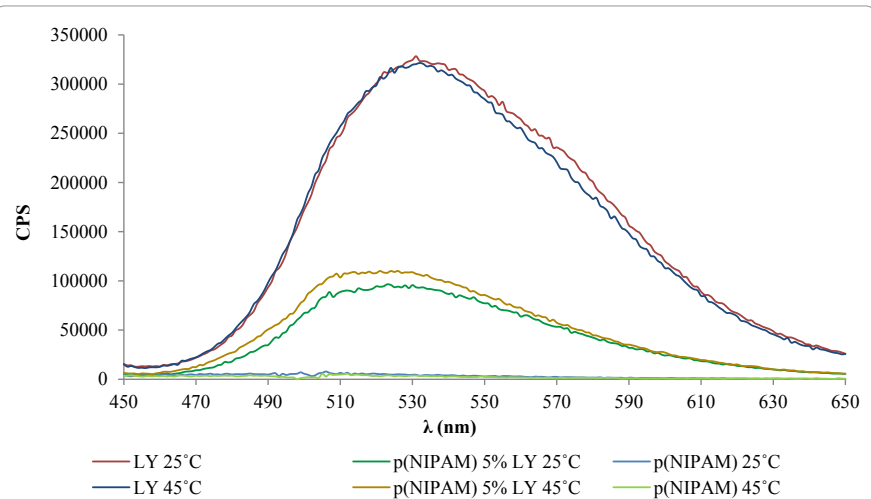

Figure 9: Fluorescence spectra of $0.01 \mu \mathrm{g} / \mathrm{mL} \mathrm{LY}, 0.2 \mu \mathrm{g} / \mathrm{mL} \mathrm{p}(\mathrm{NIPAM}-\mathrm{co}-5 \%$ $\mathrm{LY}$ ) and $0.2 \mu \mathrm{g} / \mathrm{mL} \mathrm{p}(\mathrm{NIPAM})$ excited at $430 \mathrm{~nm}$ at $\mathrm{pH} 7$ at temperatures $25^{\circ} \mathrm{C}$ and $45^{\circ} \mathrm{C}$.

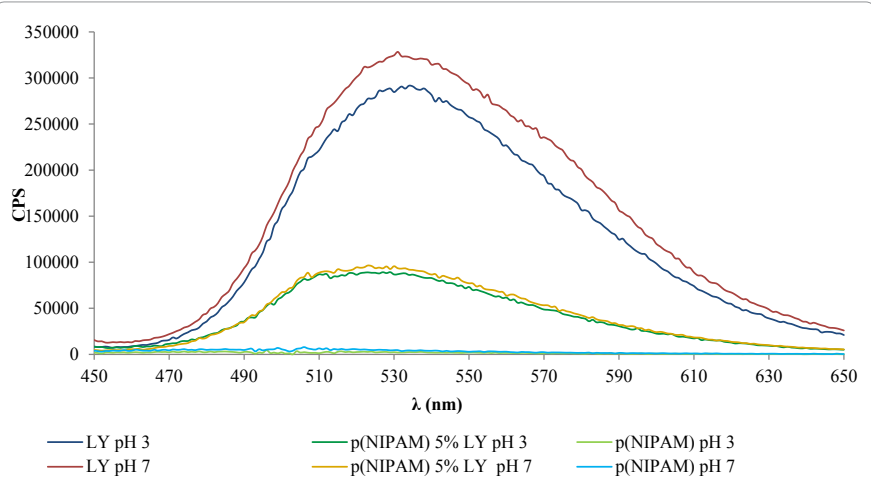

Figure 10: Fluorescence spectra of $0.01 \mu \mathrm{g} / \mathrm{mL} L Y, 0.2 \mu \mathrm{g} / \mathrm{mL}$ (NIPAM-co- $5 \%$ $\mathrm{LY}$ ) and $0.2 \mu \mathrm{g} / \mathrm{mL} \mathrm{p}(\mathrm{NIPAM})$ excited at $430 \mathrm{~nm}$ at $25^{\circ} \mathrm{C}$ at $\mathrm{pH} 3$ and 7 .

$\mathrm{p}$ (NIPAM) does not show an emission band in a similar region or of a similar intensity. On the other hand, it shows some fluorescence intensity (of much lower magnitude than $\mathrm{p}$ (NIPAM)-co-5\% LY which is thought to be due to light scattering [33]. This is a common characteristic of colloidal dispersions that is related to particle size. The turbidity of colloidal dispersions is due to the intense light scattering by its particles. The size and shape of the scattering particles are the main factors affecting the intensity of the scattered light. If a colloidal nanogel sample is placed in a UV spectrophotometer and a beam of light is passed through it, a fraction of the light will be scattered as it passes through the sample. While measuring fluorescence of $\mathrm{p}$ (NIPAM) and $\mathrm{p}$ (NIPAM)-co-5\% LY, the scattered light from the particles can partially interfere with the fluorescence emission.

Effect of temperature: The effect of temperature on the fluorescence of LY, p(NIPAM) - co- 5\% LY and p(NIPAM) can be compared using Figure 9. In 1852, Sir G. G. Stokes observed that fluorescence emission generally occurs at lower energies and longer wavelengths than that of the absorption [34]. In the case of LY, the emission band at $\mathrm{pH} 7$ at both $25^{\circ} \mathrm{C}$ and $45^{\circ} \mathrm{C}$ are similar $\lambda_{\text {max }}$, band shape and intensity. This indicates that the effect of internal conversion (due to temperature change) on the Stokes shift is minimal. In terms of fluorescence intensity, no significant difference between the fluorescence at $25^{\circ} \mathrm{C}$ and $45^{\circ} \mathrm{C}$ is seen (Figure 9). The percentage change in fluorescence intensity between both temperatures is $4 \%$ at $\mathrm{pH} 3$ and $1.6 \%$ at $\mathrm{pH} 7$.

In the case of $\mathrm{p}$ (NIPAM)-co-5\% LY, the emission bands at $25^{\circ} \mathrm{C}$ and $45^{\circ} \mathrm{C}$ (both at $\mathrm{pH}$ 7) show similar $\lambda_{\text {max }}$ and band shape. On the other hand, a change in the fluorescence intensity is observed by changing the temperature (Figure 9). The percentage change in the fluorescence intensity was $11.7 \%$ at $\mathrm{pH} 3$ (3 times higher than that of LY) and $14.6 \%$ at $\mathrm{pH} 7$ ( 9 times higher than that of LY). This can be attributed to different factors such as the change in particle size by changing the temperature from below to above the VPTT (Figure 5) which changes the fluorophore density and accordingly the fluorescence intensity. It is worth mentioning that the particle size of $\mathrm{p}$ (NIPAM)-co-5\% LY decrease by $43 \%$ when the temperature increases from $25^{\circ} \mathrm{C}$ to $45^{\circ} \mathrm{C}$ at $\mathrm{pH} 3$ and 7. The change in temperature can also cause a change in the quantum yield of fluorescence due to change in solvent properties such as solvent polarity $[18,35]$. For $\mathrm{p}(\mathrm{NIPAM})$, the particles deswell when the temperature exceeds the VPTT $\left(35^{\circ} \mathrm{C}\right)$, thus at $45^{\circ} \mathrm{C}$, they acquire a de-swollen configuration and the dispersion is more turbid. This boosts the light scattering effect which is shown here as higher fluorescence intensity.

Effect of $\mathbf{p H}$ : Lucifer yellow is a $\mathrm{pH}$ insensitive fluorescent probe [36]. This agrees with the results shown in Figure 10 where the emission bands of $\mathrm{LY}$ at same temperature $\left(25^{\circ} \mathrm{C}\right)$ and different $\mathrm{pH}$ values $(3$ and 7) are similar (same $\lambda_{e m}$ ). The same result is also shown for $\mathrm{p}$ (NIPAM)co-5\% LY.

The fluorescence intensity of LY is affected by the change in pH (Figure 10). This can be due to different factors that affect the quantum yield of the fluorophore lucifer yellow. These include; the change of the polarity of the surrounding polymer ( $($ NIPAM)) and its electrophoretic mobility which affects the polarity of the solvent [18]. Changing the solvent polarity highly affects the fluorescence lifetime which in return affects the quantum yield $[18,37,38]$. Also, the change in particle size (including expel and uptake of solvent) causes a dramatic change in the surrounding local environment. Other factors that can cause a change of the fluorescence intensity by changing the $\mathrm{pH}$ include; change in the rate of solvent relaxation and internal charge (proton) transfer [18].

\section{Microscopy}

Scanning Electron Microscopy (SEM) and Fluorescence microscopy, the nanoparticles were examined using SEM (Figure 11 ) and fluorescence microscopy (Figure 12). Figure 11 show that the particles are spherical, monodispersed and their average size is $120 \mathrm{~nm}$ which is comparable to that shown by DLS at deswollen state (Figure 5). The fluorescence microscopy (Figure 12) also confirms the results of SEM where the particles are shown to be spherical and monodispersed as well as fluorescent. Figure 12 supports the suggestion that LY is

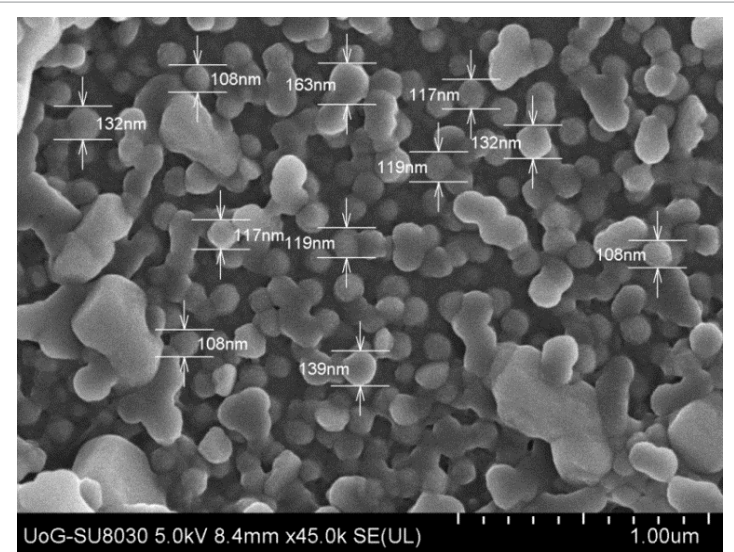

Figure 11: SEM pictures of $p($ NIPAM-co-5\% LY) at $\mathrm{pH} 3(x 45,000)$ 


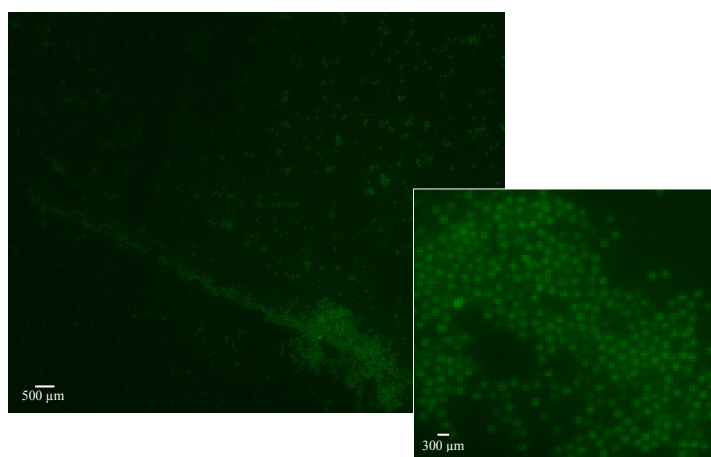

Figure 12: Fluorescence microscopy pictures of $2 \mu \mathrm{g} / \mathrm{mL}$ p(NIPAM-co-5\% LY) (x100)

incorporated in the $\mathrm{p}$ (NIPAM-co-5\% LY) nanoparticles and that they are fluorescent. Accordingly, it can be suggested that these particles can be traced in the human body (given their fluorescence) which can serve as a diagnostic tool. Researches have tried incorporating fluorescent dyes into nanogels $[39,40]$, on the other hand, there are no up-to-date data showing fluorescence microscopy images of fluorescent nanogels.

\section{Toxicity studies}

$\mathrm{p}$ (NIPAM) based nanoparticles have been studied for a number of years [41-45]. Many applications have been suggested for this polymer due to its ability to change its physico-chemical properties according to the change in environmental conditions $[3,4]$. Considering that the VPTT of $\mathrm{p}$ (NIPAM) nanoparticles is $33-35^{\circ} \mathrm{C}$ [3] which is very close to the human body temperature, many researchers investigated the possible use of $\mathrm{p}$ (NIPAM) nanoparticles in drug delivery [8,4648], delivery of stem cells [49] and other biomedical applications such as tissue engineering [27], biomedical implants [50], treatment of dentinal hypersensitivity [3] and wound dressings [51,52]. A very important point to consider in this case is the toxicity of NIPAM based nanoparticles; on the other hand, not many reports are available in this context to date.

In 2010, Naha et al. [53] studied the cyto- and geno-toxicity of $\mathrm{p}$ (NIPAM) nanoparticles (within a concentration range of 25-1000 $\mathrm{mg} / \mathrm{L}$ ) on two different mammalian cell lines, SW480 (colon) and HaCaT (dermal cell line). The viability of cells (both cell lines) after 24, 48,72 and 96 hours were shown to be $100 \%$. Also, the geno- and ecotoxicity [54] data confirmed the results of the cytotoxicity suggesting that $\mathrm{p}(\mathrm{NIPAM})$ nanoparticles have an excellent bioavailability profile in vitro. Naha et al. [53] have further studied $\mathrm{p}$ (NIPAM) based nanoparticles inside cells and concluded that the particles enter the cells and are localised in the lysosomes.

The cytotoxicity and uptake of $\mathrm{p}$ (NIPAM) based nanoparticles with incorporated hyperbranched polyglycerol (HPG) was investigated by Cuggino et al. [55]. The cytotoxic effect of p(NIPAM)-co-HPG nanoparticles on epithelial human lung cancer cell line A549, human hematopoietic cells U-937, and human epidermoid carcinoma cells A431. Results suggest that doses above $0.5 \mathrm{mg} / \mathrm{mL}$ are required to cause adverse effects on the cells. It is also worth mentioning that the particle could penetrate the cell membrane of lung cancer cells A549 incubated at $37^{\circ} \mathrm{C}$ and were distributed in the perinuclear region [55].

Herein, the effect of dextran, NIPAM monomer, p(NIPAM), $\mathrm{p}$ (NIPAM-co-5\% LY) and PEI on the cell viability of both HeLa and Vero cell lines is reported. HeLa cells are human epithelial cells of a strain maintained in tissue culture since 1951 and used in research, especially in virology. The original cells were provided by cervical carcinoma of Henrietta Lacks [56]. Vero cells are taken from the kidneys of the African green monkey, Cercopithecus aethiops sabaeus, and used to grow certain viruses for vaccine production [57].

Figure 13 shows the effect of different concentrations (concentration range between $0.03 \mu \mathrm{g} / \mathrm{mL}$ to $3 \mathrm{mg} / \mathrm{mL}$ ) of dextran, NIPAM monomer, $\mathrm{p}$ (NIPAM), p(NIPAM-co-5\% LY) and PEI on the cell viability of HeLa cells. The Figure shows that the effect of dextran (used as a negative control) on the cell viability was minimal as the cells showed over $90 \%$ viability across the whole range of concentrations. On the other hand, PEI (used a positive control) shows cell viability above $80 \%$ at concentrations less than $0.003 \mathrm{mg} / \mathrm{mL}$. When the concentration further increases, the cell viability significantly decreases till it reaches $20 \%$ at a concentration of $0.03 \mathrm{mg} / \mathrm{mL}$. In spite of its reported toxicity $[58,59]$. $\mathrm{PEI}$ is widely researched as one of the main non-viral vectors for gene therapy [60]. These results are comparable to those of Zhizhong et al. [61] who studied the cytotoxicity of linear $25 \mathrm{KD}$ PEI (known to be less toxic than branched PEI $[58,60,62])$ on OS-RC-2 cell line and reported that cell viability under $30 \mu \mathrm{g} / \mathrm{mL}$ of $25 \mathrm{kD}$ PEI was $50 \%$. For $2 \mathrm{kD}$ PEI, half of the cells were viable when the concentration was 200-300 $\mu \mathrm{g} /$ $\mathrm{mL}$. Similar results were also shown by Thomas et al. [63] who reported that less than $50 \%$ of COS-7 cells were viable when the concentration of $25 \mathrm{kD}$ PEI was more than $20 \mu \mathrm{g} / \mathrm{mL}$ while less than $5 \%$ of the cells were viable when its concentration was above $35 \mu \mathrm{g} / \mathrm{mL}$.

Despite its reported cytotoxicity [58,60-64], the use of PEI has been studied for biological applications such as gene delivery $[59,61,65,66]$, nucleic acid delivery [62,63,67-69], drug delivery [64], cosmetics [70] and tissue engineering [71]. In 2012, Wegmann et al. [72] claimed that PEI is a potent mucosal adjuvant for human use and suggested that further investigation for improvement of potency and safety of PEI as an adjuvant suggests promising results. Many attempts to decrease the cytotoxicity of PEI by conjugation with other molecules have been varied out. These aim at turning PEI into a bioequivalent delivery system $[61-63,68,69]$. Similarly, it can be suggested that the conjugation of acrylamide and its derivative NIPAM into $\mathrm{p}$ (NIPAM) based particles can yield particles with significantly lower toxicity. It is also worth mentioning that PEI is currently commercially available (in the form of PEI-HCl) in a drug in the German market known as 'Epipak' used for mouth disorders [73].

The main challenge for the use of NIPAM based particles as drug delivery systems is its toxicity. The fact that the main monomer NIPAM includes acrylamide group which is known for its toxicity [74], suggests that the polymerised particle and/or its metabolic products (such as NIPAM monomer and/or acrylamide) might acquire the same properties. Accordingly, the toxicity of the new particle $\mathrm{p}$ (NIPAMco-5\% LY), p(NIPAM) and the monomer was tested. In Figure 13, $\mathrm{p}$ (NIPAM) shows cell viability over $80 \%$ up to a concentration 3 $\mathrm{mg} / \mathrm{mL}$ while NIPAM monomer showed a high cell viability (over $80 \%$ ) for concentration equal to, or less than, $0.3 \mathrm{mg} / \mathrm{mL}$. Above this concentration, NIPAM monomer shows considerably less viability untill it reaches $10 \%$ at a dosing concentration of $3 \mathrm{mg} / \mathrm{mL}$.

For p(NIPAM-co-5\% LY) particles, the results show that the cell viability is around $80 \%$ or higher up to $3 \mathrm{mg} / \mathrm{mL}$. This suggests that $\mathrm{p}$ (NIPAM-co-5\% LY) is suitable for medical and/or pharmaceutical use when used within the specified concentrations. Similar results for the effect of the same concentrations of dextran, NIPAM monomer, $\mathrm{p}$ (NIPAM), $\mathrm{p}$ (NIPAM-co-5\% LY) and PEI on the cell viability of Vero cells. Figure 14 shows that dextran showed cell viability over $80 \%$ across all the dosing concentrations. PEI showed cell viability over $80 \%$ 


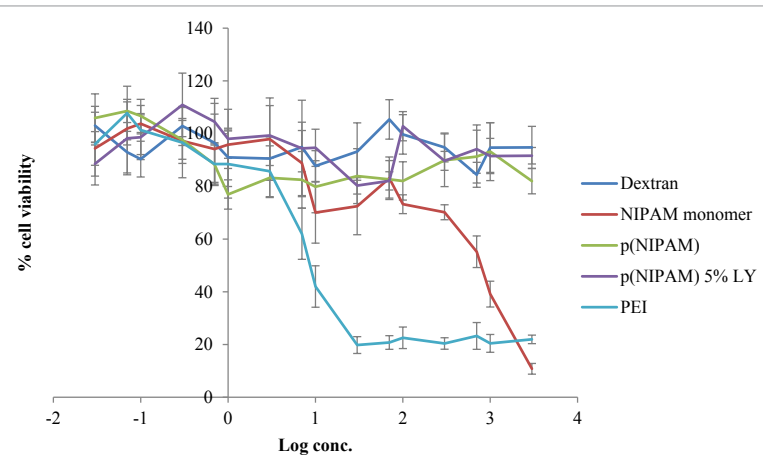

Figure 13: Percentage cell viability (after $72 \mathrm{hrs}$ ) versus log concentration (across conc. Range of $0.03 \mu \mathrm{g} / \mathrm{mL}$ to $3000 \mu \mathrm{g} / \mathrm{mL}$ ) of dextran, NIPAM monomer, $p$ (NIPAM), p(NIPAM-co-5\% LY) and PEI on $1 \times 104 \mathrm{HeLa}$ cell $/ \mathrm{mL}$.

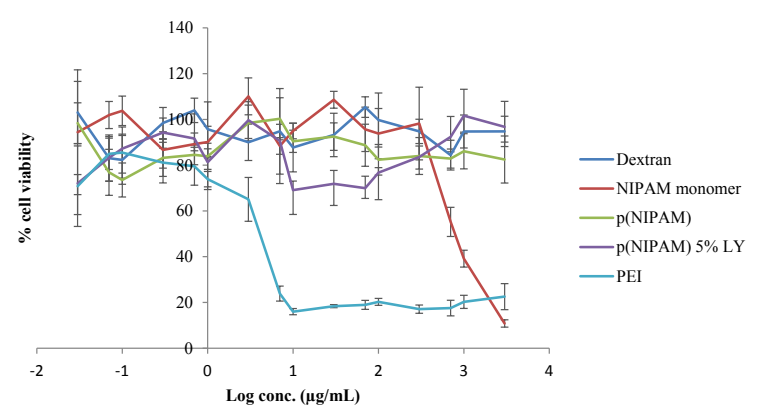

Figure 14: Percentage cell viability (after $72 \mathrm{hrs}$ ) versus log concentration (across conc. range of $0.03 \mu \mathrm{g} / \mathrm{mL}$ to $3000 \mu \mathrm{g} / \mathrm{mL}$ ) of dextran, NIPAM monomer $\mathrm{p}$ (NIPAM), p(NIPAM-co-5\% LY) and PEI on $1 \times 104$ Vero cell $/ \mathrm{mL}$.

at concentrations equal to or less than $0.001 \mathrm{mg} / \mathrm{mL}$. Increasing the dosing concentration decreased the cell viability till it reached $15 \%$ at $0.01 \mathrm{mg} / \mathrm{mL}$. NIPAM monomer showed high cell viability (between 80 and $100 \%)$ at concentrations equal to, or less than, $0.3 \mathrm{mg} / \mathrm{mL}$. Both $\mathrm{p}(\mathrm{NIPAM})$ and $\mathrm{p}$ (NIPAM-co-5\% LY) showed cell viability around $80 \%$ or more for all the dosing concentrations used.

Comparing the cytotoxicity (for both HeLa and Vero cells) of $\mathrm{p}$ (NIPAM-co-5\% LY) and $\mathrm{p}$ (NIPAM) to that of PEI shows that the former particles show a safer toxicity profile. While a concentration of $(0.7 \mu \mathrm{g} / \mathrm{mL}$ for HeLa and $3 \mu \mathrm{g} / \mathrm{mL}$ for Vero $)$ of PEI killed half of the cells (Table 2), $3 \mathrm{mg} / \mathrm{mL}$ of the NIPAM based particles kept more than $80 \%$ of the cells alive. Furthermore, NIPAM monomer which is expected to be one of the metabolic products of $\mathrm{p}$ (NIPAM) based particles has an $\mathrm{LC}_{50}$ of $700 \mu \mathrm{g} / \mathrm{mL}$ (for both HeLa and Vero cells) which is considerably higher than that of PEI. Thus, the results show that $\mathrm{p}$ (NIPAM) based particles as well as NIPAM monomer (at the specified concentrations) have a safer toxicity profile when compared to PEI. Considering the ongoing research and use of PEI in biological and pharmaceutical applications (previously discussed) and the properties of $\mathrm{p}$ (NIPAM) based particles such as temperature, $\mathrm{pH}$, ionic strength responsiveness, it is suggested that further research of the toxicity of $\mathrm{p}$ (NIPAM) based particles as well as modification of the particles can yield very useful and promising systems for biological and pharmaceutical applications such as drug delivery, gene therapy and treatment of dentinal hypersensitivity.

The biocompatibility of $\mathrm{p}$ (NIPAM), p(NIPAM-co-AA) and p(NIPAM-co-BA) with skin has been studied by Abu Samah et al. [75]. The effects of the three nanoparticles on the expression of cyclooxygenase-2 (COX-2) was determined using western blotting which showed that the particles have penetrated the skin and the keratinocytes of the vital epidermis. p(NIPAM)-co-BA showed $67 \%$ higher COX-2 expression than the control group which indicates a pro-inflammatory response. For p(NIPAM)-co-AA, no significant modulation in the expression of COX2 was shown, indicating the compatibility of the particles with skin. Comparable results were obtained for nanoparticles loaded with citric acid solution. Accordingly, the authors support the use of the multiresponsive p(NIPAM)-co-AA as a triggered or controlled topical drug delivery system.

For in vivo testing, Aslam et al. [76] tested the effect of different concentrations $(0,0.2,0.4,0.6,0.8$ and $1 \mathrm{mg} / \mathrm{mL})$ of $150 \mathrm{~nm}$ p(NIPAM) on Swiss Albino mice (Mus musculus). Oral p(NIPAM) dispersions (with the previously mentioned concentrations) were given to the mice daily for 30 days. The results suggest that lower doses $(0.2 \mathrm{mg} /$ $\mathrm{mL}$ ) had no lethal effect on the mice. Increasing the dose of $\mathrm{p}$ (NIPAM) (0.4, 0.6 and $0.8 \mathrm{mg} / \mathrm{mL}$ ), half the mice died in 20-25 days. For $1 \mathrm{mg} /$ $\mathrm{mL} \mathrm{p}$ (NIPAM) dispersions, half the mice died in 28 days. The authors suggest that $\mathrm{p}$ (NIPAM) is tolerable at low doses, on the other hand, the accumulation of high doses of the particles (by daily administration of $1 \mathrm{mg} / \mathrm{mL} / \mathrm{kg}$ ) has a lethal effect in an average of 18 days.

In 1981, Tanii et al. claimed that the metabolic product of NIPAM is acrylamide [77], accordingly, it is very important to consider its toxicity while studying the toxicity of NIPAM based particles. Many researchers have claimed that acrylamide is toxic [78], some mention its neurotoxicity [78], others mention its genotoxicity [78] as well as other serious effects such as testicular degeneration, necrosis of the liver, congestion of the lungs. Acrylamides are formed when some foods including certain nutrients are cooked at certain temperatures during grilling, frying and baking $[73,79]$. A review studying the doseresponse relationship of acrylamide was carried out by Shipp et al. [79], the study states that the reference dose (RfD) (safe dose) of acrylamide is $0.83 \mu \mathrm{g} / \mathrm{kg} / \mathrm{day}$ (considering reproductive effects and genotoxicity) and $1.2 \mu \mathrm{g} / \mathrm{kg} /$ day (considering neurotoxicity). The review also claims that most of the reports of acrylamide toxicity did not consider very important factors such as the smoking state of the patients which is extremely important [79]. Considering the RfD mentioned by Shipp et al. [79], an adult of average weight $70 \mathrm{~kg}$ can safely have $58 \mu \mathrm{g} /$ day of acrylamide.

Most of the drugs currently available in the market can cause different kind of toxicities and can even be lethal if administered at the wrong dose. It is worth mentioning at this point, that p(NIPAM) based particles (if pharmaceutically used) are intended to be used as a drug delivery system and not a drug, this might be important while calculating the required dose.

\section{Conclusion}

A novel fluorescent temperature/pH sensitive particle ( $\mathrm{p}$ (NIPAM)co-5\%LY) was successfully synthesized and characterized using different techniques. At $\mathrm{pH} 7$ and $15^{\circ} \mathrm{C}$ (the particle is swollen), the

\begin{tabular}{|c|c|c|}
\hline & $\begin{array}{c}\mathrm{LC}_{50} \text { on HeLa cells }(\mu \mathrm{g} / \\
\mathrm{mL})\end{array}$ & $\begin{array}{c}\mathrm{LC}_{50} \text { on Vero cells }(\mu \mathrm{g} / \\
\mathrm{mL})\end{array}$ \\
\hline Dextran & \multicolumn{2}{|l|}{$\geq 3000$} \\
\hline NIPAM monomer & $700( \pm 6)$ & $700( \pm 6)$ \\
\hline$p($ NIPAM) & \multicolumn{2}{|l|}{$\geq 3000$} \\
\hline$p($ NIPAM-co-5\% LY) & \multicolumn{2}{|l|}{$\geq 3000$} \\
\hline PEI & $0.7( \pm 0.2)$ & $3( \pm 0.9)$ \\
\hline
\end{tabular}

Table 2: LC $_{50}$ of dextran, NIPAM monomer, p(NIPAM), p(NIPAM-co-5\% LY) and PEI on HeLa Vero cells. 
Citation: Mohsen R, Alexander BD, Richardson SCW, Mitchell JC, Diab AA, et al. (2016) Design, Synthesis, Characterization and Toxicity Studies of Poly (N-Iso-Propylacrylamide-co-Lucifer Yellow) Particles for Drug Delivery Applications. J Nanomed Nanotechnol 7: 363. doi:10.4172/21577439.1000363

Page 9 of 10

particle size is $250 \mathrm{~nm}$. When the temperature exceeds the VPTT $\left(35^{\circ} \mathrm{C}\right)$ the particle de-swells to reach $130 \mathrm{~nm}$. These particle sizes are approximately half that of $\mathrm{p}$ (NIPAM) at similar conditions. The PdI and the intensity peaks of the new nanoparticle dispersion indicate a uniform particle size across the dispersion.

This study only provides initial evidence of the biocompatibility of NIPAM based particles and its metabolite at the specified concentrations. NIPAM monomer is more toxic than both $\mathrm{p}$ (NIPAM) and $\mathrm{p}$ (NIPAM-co-5\% LY). The two nanoparticles show cell viability over $80 \%$ (for both cell lines Hela and Vero) up to a concentration of $3 \mathrm{mg} / \mathrm{mL}$ while NIPAM monomer show cell viability over $80 \%$ equal to or less than $0.3 \mathrm{mg} / \mathrm{mL}$. At concentration of $3 \mathrm{mg} / \mathrm{mL}$, NIPAM monomer shows $10 \%$ cell viability. These data add to the few existing reports on the toxicity of NIPAM based particles and provide some encouragement around their biocompatibility and possible use for drug delivery applications.

The advantages (temperature, $\mathrm{pH}$, ionic strength, etc. responsiveness and ability to release drugs accordingly) of NIPAM based particles can be very useful medically and pharmaceutically. Such advantages can at some points be louder than other disadvantages (depends upon the case). These particles can be very useful and flexible drug delivery systems that can be used for the treatment of different diseases such as cancer and diabetes. Further studies about the ability of p(NIPAM) based particles to be used for gene and nucleic acid delivery can also be considered.

\section{References}

1. Lucifer Yellow VS dilithium salt. Sigma Aldrich, Missouri, USA.

2. 4-Amino-3,6-disulfo-1,8-naphthalic anhydride dipotassium salt. Sigma Aldrich, Missouri, USA

3. Mohsen R, Vine GJ, Majcen N, Alexander BD, Snowden MJ (2013) Characterization of thermo and $\mathrm{pH}$ responsive NIPAM based microgels and their membrane blocking potential. Colloids and Surfaces A: Physicochemical and Engineering Aspects 428: 53-59.

4. Saunders BR, Laajam N, Daly E, Teow S, Hu X, et al. (2009) Microgels: From responsive polymer colloids to biomaterials. Adv Colloid Interface Sci 147-148: 251-62.

5. Ma X, Tang X (2006) Flocculation behavior of temperature-sensitive poly ( $\mathrm{N}$-isopropylacrylamide) microgels containing polar side chains with $-\mathrm{OH}$ groups. Journal of Colloid and Interface Science 299: 217-224.

6. Thorne JB, Vine GJ, Snowden MJ (2011) Microgel applications and commercial considerations. Colloid Polym Sci 289: 625-646.

7. Pinkrah VT, Beezer AE, Chowdhry BZ, Gracia LH, Cornelius VJ, et al. (2005) Swelling of cationic polyelectrolyte colloidal microgels: Thermodynamic considerations. Colloids and Surfaces A Physicochemicaland Engineering Aspects 262: 76-80.

8. Ramkissoon-Ganorkar C, Liu F, Baudys M, Kim SW (1999) Modulating insulin release profile from $\mathrm{pH}$ thermosensitive polymeric beads through polymer molecular weight. Journal of Controlled Release 59: 287-298.

9. Lopez VC, Hadgraft J, Snowden MJ (2005) The use of colloidal microgels as a (trans)dermal drug delivery system. Int J Pharm 292: 137-147.

10. Pelton R (2000) Temperature-sensitive aqueous microgels. Adv Colloid Interface Sci 85: 1-33.

11. Yasui M, Shiroya T, Fujimoto K, Kawaguchi H (1997) Activity of enzymes immobilized on microspheres with thermosensitive hairs. Colloids and Surfaces B: Biointerfaces 8: 311-319.

12. Kondo A, Oku S, Higashitani K (1991) Adsorption of gamma-globulin, a mode protein for antibody, on colloidal particles. Biotechnol Bioeng 37: 537-543.

13. Kitano H, Nakamura K, Hirai Y, Kaku T, Ise N (1998) Restricted diffusion effect on the binding of protiens to porous polymer resins as studied by repetitive injection method. Biotechnology and Bioengineering 31: 547-552.
14. Wu W, Chen S, Hu Y, Zhou S (2012) A fluorescent responsive hybrid nanoge for closed-loop control of glucose. J Diabetes Sci Technol 6: 892-901.

15. Ravaine V, Ancla C, Catargi B (2008) Chemically controlled closed-loop insulin delivery. J Control Release 132: 2-11.

16. Sabnis RW (2010) Handbook of biological dyes and stains. Synthesis and industrial applications. Wiley, New-Jersey, USA.

17. Caffeine Product Information. Sigma Aldrich, Missouri, USA.

18. Urstenberg A, Vauthey E (2005) Excited-state dynamics of the fluorescent probe Lucifer Yellow in liquid solutions and in heterogeneous media. Photochemical \& Photobiological Sciences 4: 260-267.

19. Oheme I, Wolfbeis OS (1997) Optical sensors for determination of heavy metal ions. Microchimica Acta 126: 177-192.

20. ACD/Labs. Advanced Chemistry Development Inc., Ontario, Canada.

21. Heller MJ, Jablonski EJ (1990) Fluorescent stokes shift probes for polynucleotide hybridization assays.

22. Buetow DE, Cameron IT, Padilla GM, Zimmerman AM, Stevens JK, et al. (1994) Three-Dimensional Confocal Microscopy: Volume Investigation of Biological Specimens.

23. Instructions of FITC and TRITC. Thermo Scientific

24. Instructions of Texas Red Sulfonyl Chloride. Thermo Scientific.

25. Lucifer Yellow CH Dilitium salt. Fluorophores.

26. (1984) Fluorescence Quantum Yield Standards.

27. Thorne JB, Vine GJ, Snowden MJ (2011) Microgel applications and commercial considerations. Colloid and Polymer Science 289: 625-646.

28. Thorne JB (2012) Controlling the interfacial behaviour of colloidal microge systems. University of Greenwich, London, UK.

29. Elaissari A (2003) Colloidal Biomolecules, Biomaterials, and Biomedical Applications.CRC Press, Lyon, France.

30. Alarcon CD, Twaites B, Cunliffe D, Smith JR, Alexander C (2005) Grafted thermo and $\mathrm{pH}$ responsive co-polymers: Surface-properties and bacteria adsorption. International Journal of Pharmaceutics 295: 77-91.

31. Ballatori N, Hager DN, Nundy S, Miller DS, Boyer JL (1999) Carrier-mediated uptake of lucifer yellow in skate and rat hepatocytes: a fluid-phase marker revisited. Gastrointest Liver Physiol 40: G896-G904.

32. Tsuji S, Kawaguchi $H$ (2005) Colored thin films prepared from hydroge microspheres. Langmuir 21: 8439-8442.

33. Lakowicz JR (2007) Principles of Fluorescence Spectroscopy. Springer, Baltimore, USA.

34. Herron JN, Jiskoot W, Crommelin DJ (1995) Physical methods to characterize pharmaceutical proteins. Pharmaceuticsl Biotechnology 7.

35. Steinberg TH, Newman AS, Swanson JA, Silverstein SC (1987) Macrophages possess probenecid-inhibitable organic anion transporters that remove fluorescent dyes from the cytoplasmic matrix. J Cell Biol 105: 2695-2702.

36. Pant S, Tripathi HB, Pant DD (1995) Solvent polarity and viscosity effect on the fluorescence spectrum and excited state lifetime of quinine dication. Journal of Photochemistry and Photobiology A: Chemistry 85: 33-38.

37. Baruah M, Qin W, Flors C, Hofkens J, Valle RA, et al. (2006) Solvent and $\mathrm{pH}$ Dependent Fluorescent Properties of a Dimethylaminostyryl Borondipyrromethene Dye in Solution. J Phys Chem A 110: 5998-6009.

38. Stephan D, Sbai O, Wen J, Couraud PO, Putterman C, et al. (2013) TWEAK Fn14 pathway modulates properties of a human microvascular endothelial cell model of blood brain barrier. Journal of Neuroinflammation 10: 9 .

39. Zenkl G, Klimant I (2009) Fluorescent acrylamide nanoaprticles for boronic acid sugar sensing - from probes to sensors. Microchim Acta 166: 123-131.

40. Yin J, Guan X, Wang D, Liu S (2009) Metal-Chelating and Dansyl-Labeled Poly(Nisopropylacrylamide) Microgels as Fluorescent Cu2+ Sensors with Thermo-Enhanced Detection Sensitivity. Langmuir 25: 11367-11374.

41. Saunders BR, Crowther HM, Morris GE, Mears SJ, Cosgrove T, et al. (199) Factors affecting the swelling of poly( $\mathrm{N}$-isopropylacrylamide) microge particles: fundamental and commercial implications. Colloids and Surfaces A-Physicochemical and Engineering Aspects 149: 57-64. 
Citation: Mohsen R, Alexander BD, Richardson SCW, Mitchell JC, Diab AA, et al. (2016) Design, Synthesis, Characterization and Toxicity Studies of Poly (N-Iso-Propylacrylamide-co-Lucifer Yellow) Particles for Drug Delivery Applications. J Nanomed Nanotechnol 7: 363. doi:10.4172/21577439.1000363

Page 10 of 10

42. Gracia LH, Snowden MJ (2007) Handbook of Industrial water soluble polymers.

43. Crowther HM, Saunders BR, Mears SJ, Cosgrove T, Vincent B, et al. (1999) Poly(NIPAM) microgel particle deswelling: a light scattering and small-angle neutron scattering study. Colloids and Surfaces A: Physicochemical and Engineering Aspects 152: 327-333.

44. Ali MM, Aguirre SD, Xu Y, Filipe CD, Pelton R, et al. (2009) Detection of DNA using bioactive paper strips. Chem Commun (Camb) : 6640-6642.

45. Pelton RH (1986) Chibante P. Preparation of aqueous lattices with Nisopropylacrylamide. Colloids and Surfaces 20: 247-256.

46. Lopez VC, Hadgraft J, Snowden MJ (2005) The use of colloidal microgels as a (trans)dermal drug delivery system. Int J Pharm 292: 137-147.

47. Hazot P, Delair T, Pichot C, Chapel JP, Elaissari A (2003) Poly(Nethylmethacrylamide)thermally-sensitive microgel latexes: Effect of the nature of the crosslinker on the polymerization kinetics and physicochemical properties. Comptes Rendus Chimie 6: 1417-1424.

48. Oh JK, Drumright R, Siegwart DJ, Matyjaszewski K (2008) The development of microgels/nanogels for drug delivery applications. Prog Polym Sci 33: 448-477.

49. Kurdi M, Chidiac R, Hoemann C, Zouein F, Zgheib C, et al. (2010) Hydrogels as a platform for stem cell delivery to the heart. Congest Heart Fail 16: 132-135.

50. Bridges AW, Singh N, Burns KL, Babensee JE, Andrew Lyon L, et al. (2008) Reduced acute inflammatory responses to microgel conformal coatings. Biomaterials 29: 4605-4615.

51. Lin SY, Chen KS, Liang RC (2001) Design and evaluation of drug-loaded wound dressing having thermo responsive, adhesive, absorptive and easy peeling properties. Biomaterials 22: 2999-3004.

52. Lin FH, Tsai JC, Chen TM, Chen KS, Yang JM, et al. (2007) Fabrication and evaluation of auto-stripped tri-layer wound dressing for extensive burn injury. Materials Chemistry and Physics 102: 152-158.

53. Naha PC, Bhattacharya K, Tenuta T, Dawson KA, Lynch I, et al. (2010) Intracellular localisation, geno- and cytotoxic response of polyNisopropylacrylamide (PNIPAM) nanoparticles to human keratinocyte (HaCaT) and colon cells (SW 480). Toxicol Lett 198: 134-143.

54. Naha P, Casey A, Tenuta T, Lynch I, Dawson KA, et al. (2009) Preparation, characterization and ecotoxicological evaluation of four environmentally relevant species of $\mathrm{N}$-isopropylacrylamide and $\mathrm{N}$-isopropylacrylamide-co- $\mathrm{N}$ tertbutylacrylamide copolymer nanoparticles. Dublin Institute of Technology, Articles Radiation and Environmental Science Centre 92: 146-154.

55. Cuggino JC, Alvarez $\mathrm{Cl}$, Strumia MC, Welker $\mathrm{P}$, Licha $\mathrm{K}$, et al. (2011) Thermosensitive nanogels based in dendritic polyglycerol and $\mathrm{N}$-isopropylacrylamide. Soft Matter 7: 11259-11266.

56. Gold M (1986) A Conspiracy of Cells: One woman's Immortal Legacy-And the Medical Scandal It Caused.

57. Voevodin AF, Marx PA (2009) Simian Virology. John Wiley \& Sons, New Delhi, India.

58. Kafil V, Omidi Y (2011) Cytotoxic impacts of linear and branched polyethylenimine nanostructures in a431 cells. Bioimpacts 1: 23-30

59. Florea BI, Meaney C, Junginger HE, Borchard G (2002) Transfection efficiency and toxicity of polyethylenimine in differentiated Calu- 3 and nondifferentiated COS-1 cell cultures. AAPS PharmSci 4: E12.

60. Okon EU, Hammed G, El-Wafa PA, Abraham O, Case N, et al. (2014) In-vitro cytotoxicity of Polyethyleneimine on HeLa and Vero Cells. International Journal of Innovation and Applied Studies 5:192-199.

61. Xu Z, Shen G, Xia X, Zhao X, Zhang P, et al. (2011) Comparisons of three polyethyleneimine-derived nanoparticles as a gene therapy delivery system for renal cell carcinoma. Journal of Translational Medicine 9: 46.

62. Dahai J (2011) Application of polymers in nucleic acid delivery.

63. Thomas M, Ge Q, Lu JJ, Chen J, Klibanov AM (2005) Cross-linked Smal Polyethylenimines: While Still Nontoxic, Deliver DNA Efficiently to Mammalian Cells in Vitro and in Vivo. Pharmaceutical Research 22: 373-380.

64. Bauer JA, Rao W, Smith DJ (1988) Evaluation of linear polyethyleneimine/ nitric oxide adduct on wound repair: therapy versus toxicity. Wound Repair and Regeneration 6: 569-577.
65. Wang X, Zhou L, Ma Y, Li X, Gu H (2002) Control of Aggregate Size of Polyethyleneimine-Coated Magnetic Nanoparticles for Magnetofection. Nano Res 2: 365-372.

66. Sharma A, Tandon A, Tovey JC, Gupta R, Robertson JD, et al. (2011) Polyethylenimine-conjugated gold nanoparticles: Gene transfer potential and low toxicity in the cornea. Nanomedicine 7: 505-513.

67. Lee M (2007) Apoptosis Induced by Polyethylenimine/DNA Complex in Polymer Mediated Gene Delivery. Bull Korean Chem Soc 28: 95-98.

68. Han SE, Kang H, Shim GY, Kim SJ, Choi HG, et al. (2009) Cationic derivatives of biocompatible hyaluronic acids for delivery of siRNA and antisense oligonucleotides. Journal of Drug Targeting 17: 123-132.

69. Huang YP, Lin IJ, Chen CC, Hsu YC, Chang CC, et al. (2013) Delivery of small interfering RNAs in human cervical cancer cells by polyethyleniminefunctionalized carbon nanotubes. Nanoscale Research Letters 8: 267-278.

70. (1973) Polyethylenimine Shampoo Compositions.

71. Khanam N, Mikoryak C, Draper RK, Balkus KJ Jr (2007) Electrospun linear polyethyleneimine scaffolds for cell growth. Acta Biomater 3: 1050-1059.

72. Wegmann F, Gartlan KH, Harandi AM, Brinckmann SA, Coccia M, et al. (2012) Polyethyleneimine is a potent mucosal adjuvant for glycoproteins with innate and adaptive immune activating properties. Nat Biotechnol 30: 883-888.

73. The Complete Drug Reference. Pharmaceutical Press, London, UK.

74. U.S. Department of Health and Human Services. Toxicological profile for acrylamide.

75. Abu Samah NH, Heard CM (2014) The effects of topically applied polyNIPAMbased nanogels and their monomers on skin cyclooxygenase expression, ex vivo. Nanotoxicology 8: 100-106.

76. Aslam I, Verma RK, Roy R, Roy SP (2013) Synthesis of polymeric nanoparticle "pnipam" poly ( $\mathrm{N}$-isopropylacrylamide) and their toxicity assay on Swiss albino mice Mus musculus. Indian Journal of Fundamental and Applied Life Sciences 3: 116-119.

77. Tanii H, Hashimoto K (1981) Studies on in vitro metabolism of acrylamide and related compounds. Arch Toxicol 48: 157-166.

78. US Department of Health and Human Services, Occupational safety and health guideline for acrylamide.

79. Shipp A, Lawrence G, Gentry R, McDonald T, Bartow H, et al. (2006) Acrylamide: review of toxicity data and dose-response analyses for cancer and noncancer effects. Crit Rev Toxicol 36: 481-608. 